\title{
El uso de hierbas medicinales puede producir graves problemas nefrológicos y urológicos
}

\author{
O. Arango Toro \\ Servicio de Urología. Hospital del Mar, Barcelona \\ Universidad Autónoma de Barcelona
}

Actas Urol Esp 2005; 29 (8): 801-802

A raíz de las imágenes del Dr. Peyrí sobre "La otra fitoterapia en Urología” publicadas en Actas Urol Esp 2005; 29(7): 721 , he considerado oportuno comentar algunos hechos catastróficos ocurridos en los últimos años con el uso descontrolado de hierbas medicinales en nuestra especialidad y realizar algunas reflexiones sobre los peligros que entraña su uso creciente.

A pesar de los grandes progresos de la medicina y de la industria farmacéutica, los cuales han hecho posible el desarrollo de fármacos específicamente diseñados para corregir alteraciones moleculares concretas, cuyos resultados están avalados por una rigurosa metodología científica y una normativa legal estricta, sorprende que el consumo de hierbas con fines medicinales sigue aumentando tanto en Europa como en los EEUU, estimándose que en este país se gastaron en el año 2001 más de 4.200 millones de dólares en hierbas y productos botánicos.

Gue las plantas han tenido y seguirán teniendo un papel terapéutico destacado en la medicina es un hecho incontrovertible. Buen ejemplo de ello lo tenemos en la fitoterapia para la HBP, en la que los principios activos de las plantas han sido aislados, dosificados y producidos científicamente bajo estricto control de calidad, de ahí que cada vez disponemos de mayor número de evidencias que avalan su seguridad y eficacia terapéutica. El problema que nos preocupa es muy diferente y se deriva del consumo descontrolado de hierbas secas con fines medicinales, en el cual están implicados factores tan dispares y complejos como:

- El difícil control de este mercado y la falta de una regulación actualizada, lo que facilita la adulteración de los preparados botánicos por parte de comerciantes sin escrúpulos o ignorantes

- La interacción entre las hierbas medicinales y los medicamentos convencionales

- La contaminación accidental de las plantas con bacterias y hongos tóxicos

- La contaminación intencionada con moléculas farmacológicamente activas

- La falta de estandarización propia de las plantas debido a la diversidad genética y a los cambios del medio en el que se desarrollan, lo que condicionan una gran variabilidad en la concentración de las sustancias contenidas en ellas

- Y el desconocimiento de los efectos adversos derivados de su uso, ya que habitualmente éstos se ocultan y no se informan a las autoridades sanitarias ni a los consumidores.
No obstante, los problemas más graves relacionados con el consumo de hierbas medicinales son debidos a las sustancias tóxicas presentes en las plantas. Un claro ejemplo de ello lo tenemos en la nefritis intersticial rápidamente progresiva y el carcinoma urotelial múltiple producidos por el consumo de plantas del genero Aristolochia, cuyo agente tóxico es el ácido aristolóquico. Este género cuenta con unas 320 especies en todo el mundo, distribuidas en las zonas templadas de ambos hemisferios, excepto el Austral. De las 12 especies de Aristolochia reportadas en Europa, 8 se encuentran en España, en donde su uso con fines medicinales es corriente y viene recomendado en algunos libros de medicina popular y plantas medicinales, que les atribuyen propiedades diuréticas, antiinfecciosa de las vias urinarias, antirreumáticas y sedante.

En la literatura médica reciente han sido publicados varios casos de nefritis intersticial en mujeres jóvenes debido al consumo de hierbas chinas para adelgazar que contenían especies del género Aristolochia, de ahí que a esta forma de nefritis fibrosante, rápidamente progresiva e irreversible, se le denomine genéricamente "nefropatía por hierbas chinas"1-4. Uno de estos casos ocurrió en España, en la provincia de Lérida, y fue ocasionado por el consumo de Aristolochia pistolochia ${ }^{5}$. Sin embargo, la situación más dramática fue publicada en el New England Journal of Medicine en el año 2000 y ocurrió en Bélgica, en donde un herborista sustituyo en un preparado de hierbas chinas para adelgazar, la Stephania tetrandra por la Aristolochia fangchi, dado que ambas plantas reciben el mismo nombre vernáculo en china. De las 105 mujeres jóvenes que consumieron este preparado de forma continuada, 43 desarrollaron insuficiencia renal terminal por nefropatía intersticial fibrosante, de las cuales 31 fueron trasplantadas y 12 permanecían en hemodiálisis. Teniendo en cuenta el potente efecto carcinogénico del ácido aristolóquico, 39 pacientes aceptaron que se les realizara una nefroureterectomía profiláctica y en 18 de ellas se encontró un carcinoma urotelial de vías urinarias superiores o de vejiga, en 19 una displasia severa y solamente 2 tenían el urotelio normal ${ }^{6-8}$.

Los ácidos aristolóquicos, son un conjunto de derivados nitrofenantrénicos altamente tóxico, con potente acción mutágena dado su capacidad de formar enlaces covalentes con el DNA celular. Diversos estudios moleculares en animales de experimentación y en biopsias de urotelio han demostrado la presencia de estos enlaces, y han puesto de manifiesto alteraciones en los oncogenes $\mathrm{H}-$ ras y p53 que impiden el proceso de reparación del DNA y 
permiten su replicación defectuosa dando origen al carcinoma $^{9-11}$. Algunos autores han sugerido que la dosis total acumulativa de Aristolochia constituye un factor de riesgo determinante para el desarrollo del carcinoma urotelial, habiéndose calculado que una dosis superior a $200 \mathrm{~g}$. supone un riesgo elevado para el desarrollo del tumor. Sin embargo, un reciente estudio experimental en ratas sugiere que el ácido aristolóquico administrado de forma aguda a dosis elevadas tiene el mismo efecto carcinogénico que las dosis pequeñas repetidas ${ }^{12}$.

Como medida cautelar, las autoridades sanitarias de la mayoría de los países europeos, EEUU, Canadá, Australia y Japón, han prohibido la venta, suministro e importación de todas las especies y derivados galénicos que contengan plantas del género Aristolochia, así como también de otras especies que pueden contener ácido aristolóquico o que pueden ser confundidas con otras especies de Aristolochia, tales como: Akebia spp., Asarun spp., Bragantia spp., Clematis spp., Cocculus spp., Diploclisia spp., Menispermum spp., Stephania spp., Saussurea lappa, Sinomenium acutum y Vladimiria souliei. Completando la prohibición, se incluyen algunos nombres vulgares de plantas como: "Mu Tong", "Fangji" o "Fang Ji".

Para terminar cabe plantearnos la siguiente pregunta ¿si la mayoría de los ciudadanos europeos tienen acceso a una medicina de calidad, porqué sigue creciendo el consumo descontrolado de hierbas medicinales?. Ciertamente no es fácil dar una respuesta sencilla a esta pregunta y

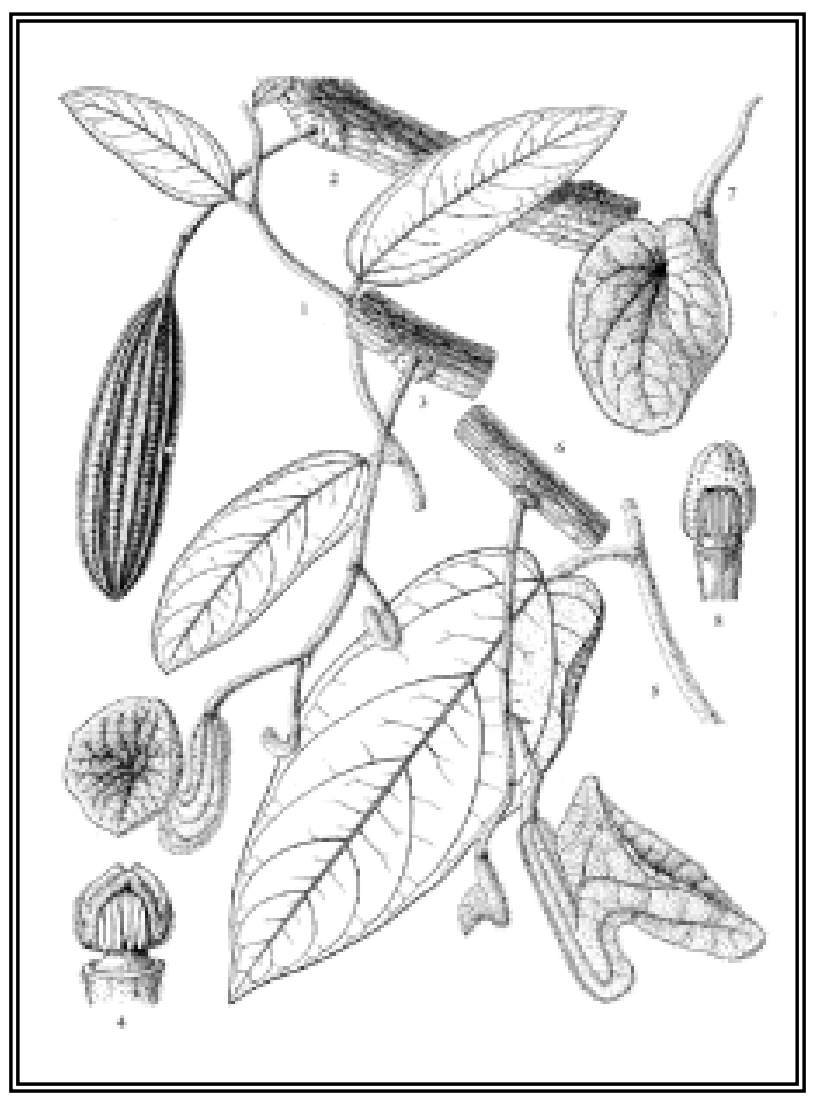

FIGURA 1. Aristolochia fangchi, especie responsable de varios casos de nefritis intersticial rápidamente progresiva y carcinoma transicional, en mujeres jóvenes que consumian hierbas chinas para adelgazar. estamos convencidos de que influyen factores tan dispares como la falta de control sanitario de este mercado; la falta de información y educación sanitaria; la creencia de que todo lo natural es inocuo; el arraigo de costumbres y tradiciones centenarias, especialmente en el área rural; el alto coste de los medicamentos; o el engaño de curanderos y otros personajes sin escrúpulos que los adulteran, como está ocurriendo con los preparados naturales para la impotencia, los cuales están siendo mezclados con sildenalfilo y tadalafilo ${ }^{13}$; $\sin$ dejar de lado el potente efecto placebo que siempre han tenido las hierbas, actualmente potenciado por el hecho de que todo lo natural o ecológico está de moda en una sociedad cada vez más tecnificada.

\section{REFERENCIAS}

1. Tanaka A, Shinkai S, Kasuno K, et al. Chinese herbs nephropathy in the Kansai area: a warning report. Jpn J Nephrol 1997;39:438-440.

2. Lord GM, Tagore R, Cook T, Gower P, Pusey CD. Nephropathy caused by Chinese herbs in the UK. Lancet 1999; 354:481-482.

3. Yang C-S, Lin C-H, Chang S-H, Hsu H-C. Rapidly progressive fibrosing interstitial nephritis associated with Chinese herbal drugs. Am J Kidney Dis 2000;35:313-318.

4. Pourrat J, Montastruc JL, Lacombe JL, Cisterne JM, Rascol O, Dumazer P. Nephropathy associated with Chinese herbal drugs. 2 cases. Presse Med 1994; 23:16691670

5. Peña JM, Borrás M, Ramos J, Montoliu J. Rapidly progressive interstitial renal fibrosis due to a chronic intake of a herb (Aristolochia pistolochia) infusion. Nephrol Dial Transplant 1996;11:1359-1360.

6. Nortier JL, Martinez MC, Schmeiser HH, Arlt VM, Bieler CA, Petein M, et al. Urothelial carcinoma associated with the use of a Chinese herb (Aristolochia fangchi). N Engl J Med 2000;342:1686-1692.

7. Martinez MCM, Nortier JL, Vereerstraeten P, Vanherweghem, JL. Progression rate of Chinese herb nephropathy: impact of Aristolochia fangchi ingested dose. Nephrol Dial Transplant 2002;17:408-412.

8. Nortier JL, Schmeiser HH, Martinez MCM, Arlt VM, Vervaet $\mathrm{C}$, Garbar $\mathrm{CH}$, et al. Invasive urothelial carcinoma after exposure to Chinese herbal medicine containing aristolochic acid may occur without severe renal failure. Nephrol Dial Transplant 2003;18:426-428.

9. Schmeiser HH, Bieler CA, Wiessler M, Ypersele de Strihou C van, Cosyns JP. Detection of DNA adducts formed by aristolochic acid in renal tissue from patients with Chinese herbs nephropathy. Cancer Research 1996;56:2025-2028.

10. Stiborova M, Frei E, Sopko B, Wiessler M, Schmeiser HH. Carcinogenic aristolochic acids upon activation by DT-diaphorase form adducts found in DNA of patients with Chinese herbs nephropathy. Carcinogenesis 2002;23:617-625.

11. Arlt VM, Stiborova M, Schmeiser HH. Aristolochic acid as a probable human cancer hazard in herbal remedies: a review. Mutagenesis 2002;17:265-277.

12. Cui M, Liu ZH, Qiu Q, Li H, Li LS. Tumour induction in rats following exposure to short-term high dose aristolochic acid I. Mutagenesis 2005;20:45-49.

13. Fleshner N, Harvey M, Adomat H, Wood C, Eberding A, Hersey K, Guns E. Evidence for contamination of herbal erectile dysfunction products with phosphodiesterase types 5 inhibitors. J Urol 2005; 174:636-641.

Dr. O. Arango Toro

Loreto, $24-26$ - Esc. B - $4^{\mathrm{o}}-2^{\mathrm{a}}$

08029 Barcelona

e-mail: oarango@imas.imim.es 